\title{
Mudanças organizacionais no processo de modernização da Secretaria da Fazenda do Estado de Pernambuco
}

Clara Emilie Boeckmann e Nevton Borba de Andrade

\section{Introdução}

A Sefaz é o órgão estadual que tem como missão "Prover e gerir os recursos financeiros necessários à implementação das políticas públicas do Estado”. Seu corpo funcional é composto por cerca de 2.400 funcionários. O enfoque deste trabalho está centrado no Grupo Ocupacional de Auditores do Tesouro Estadual (Goate), composto por auditores I e II, que juntos representam em torno de $50 \%$ dos funcionários fazendários. Os auditores I são responsáveis pela fiscalização de mercadorias em trânsito, arrecadação e controladoria financeira, enquanto os auditores II são responsáveis por auditorias de estabelecimentos, administração financeira/contábil e auditoria interna.

A Sefaz atua em todo o território do Estado de Pernambuco, por meio de estabelecimentos fixos (80 prédios), como as Agências da Receita Estadual (AREs) e os Postos Fiscais (PFs), e de estabelecimentos móveis, destinados a trabalhos de acompanhamento e fiscalização, como "volantes" e equipes de fiscalização. 
$\mathrm{Na}$ atual conjuntura, as profundas mudanças no campo social, econômico e tecnológico têm afetado não só a sociedade e as empresas, mas, sobremaneira, o governo brasileiro. Essas mudanças, juntamente com as dificuldades políticas e econômicas do País, tinham grandes repercussões na Sefaz. Além desses problemas, a Sefaz possuía estrutura organizacional pesada e complexa, devido à existência de grande quantidade de níveis hierárquicos e pouca integração entre as várias áreas de planejamento e de ação fiscal. Apresentava processo bastante lento e burocrático de atendimento e prestação de serviços ao contribuinte e à sociedade, com predomínio de intervenções empíricas no processo de planejamento, baixo nível de automação dos processos e pouca ênfase no processo de divulgação de informações, demonstrando existir pouca transparência na gestão, entre outros problemas.

A partir de 1998, teve início o Programa de Modernização da Administração Fazendária (Promofaz), que tem concentrado esforços na implantação de projetos estruturadores, como os novos modelos de controle interno, de planejamento e ação fiscal e de tecnologia da informação (TI), dando origem ao novo modelo de gestão organizacional. Dentre os projetos de TI, destacaram-se a implantação da rede corporativa de dados e voz e a elaboração das arquiteturas de sistemas e tecnológicas, para o desenvolvimento e a operacionalização dos novos sistemas corporativos.

O Promofaz promoveu mudanças significativas e trouxe inúmeros benefícios à instituição, sintetizados no Relatório de Gestão 1999/2002 da Sefaz (Pernambuco, 2003) e nos Planos Estratégicos publicados entre 2004 e 2006. O Plano Estratégico 2004-2007 também aponta para o sucesso da maioria dos indicadores de desempenho do Plano Plurianual (PPA) 2000-2003 (Pernambuco, 2004). Esses resultados estão refletidos, inclusive, na arrecadação do ICMS entre 1999 e 2005 (Figura 1).

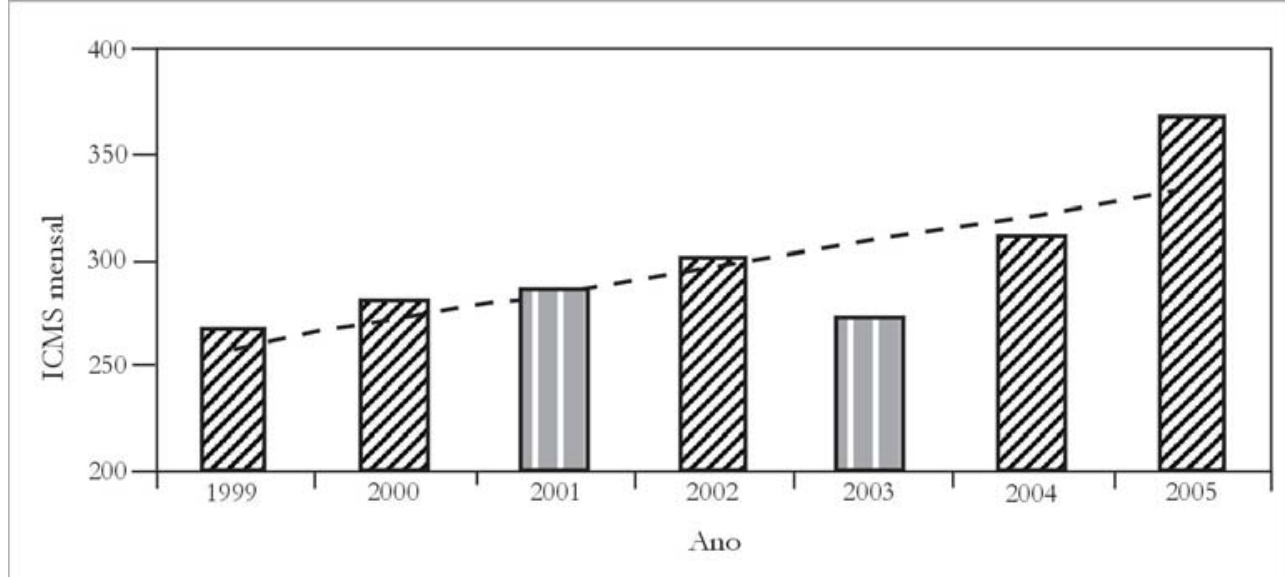

Fonte: Pernambuco (2003) - Relatório de Gestão 1999/2002

Figura 1: Evolução real da arrecadação média mensal do ICMS de Pernambuco, entre 1999 e 2002, em milhões de reais, ao valor de setembro/2002 IGP-DI (FGV) 
Este trabalho tem como objetivo avaliar as principais mudanças organizacionais que ocorreram na Sefaz entre 1998 e 2005. Seu principal enfoque está centrado nos impactos do processo de modernização tecnológica como apoio à execução das tarefas, ao planejamento e ao novo sistema de gestão, que têm gerado reflexos, principalmente, na melhoria do desempenho da instituição e na prestação de serviços e informações ao governo, cidadão e contribuinte. O trabalho é baseado em dados observados pelos próprios autores, que participaram do processo de modernização fazendária, e em informações disponíveis em relatórios da instituição. Esses dados foram contrapostos à luz do referencial teórico julgado pertinente.

\section{Breve histórico do processo de modernização fazendária}

A primeira tentativa de modernização fazendária, considerando os dois últimos governos do Estado de Pernambuco, aconteceu por volta de 1995, mas os trabalhos foram encerrados sem sucesso. Em 1996, surge nova oportunidade para essa modernização por meio de um projeto não apenas de mudança tecnológica, mas de modernização do modelo de gestão das Secretarias da Fazenda dos estados, do Distrito Federal e da Receita Federal da União, cujos trabalhos para implementação foram iniciados apenas em 1998.

Nesse novo contexto, em que se buscava realizar um trabalho de modernização da organização, e não apenas de uma área específica, procurou-se focar sua atuação abordando três grandes linhas de ação: a) levantamento e diagnóstico da situação organizacional; b) construção de subprojetos para o novo modelo de gestão, modernização do ambiente tecnológico e adaptação da infra-estrutura; e c) capacitação de todo o seu quadro de pessoal.

Esse trabalho atingiu maior aceleração a partir de 1999, quando foram realizadas diversas etapas do projeto, destacandose: a) o levantamento do clima organizacional; b) a elaboração de projeto de desenvolvimento de competências; c) o levantamento e a revisão dos processos produtivos; d) a especificação e elaboração de alguns modelos de gestão para as diferentes áreas de atuação, em consonância com o modelo de gestão da instituição. Dentre esses modelos, destaca-se a elaboração de novo modelo de gestão da área de tecnologia da informação, sustentado na definição de modernas arquiteturas de sistema computacional. Esse novo modelo viria a ser um dos pontos de sustentação na informatização dos processos produtivos e na implantação e consolidação da nova estrutura organizacional idealizada para apoiar o processo de gestão por resultados.

Em todo esse conjunto de ações, procurou-se estabelecer o desenvolvimento do trabalho visando a não só efetuar o diagnóstico da organização, mas a aproveitar o momento de ingresso de grande contingente de recursos humanos, com as mais variadas formações e experiências, para realizar um trabalho de revisão dos seus processos produtivos, de forma a implantar-se o novo modelo de gestão na secretaria. Assim, foram quebrados "velhos" paradigmas existentes na administração pública, voltando-se para uma gestão por resultados, em que o foco do gerenciamento está nos fins, isto é, na produção de resultados.

Um dos elementos importantes no processo de modernização da Sefaz foi o último concurso público, ocorrido em 
1992, para as funções de auditores, tendo sido contratados, entre aquele ano e 1996, cerca de 700 novos funcionários, a maioria deles com formação em nível superior.

Esses funcionários passaram por treinamento intensivo, abrangendo desde os aspectos técnicos de fiscalização, contabilidade, finanças e auditoria até os aspectos éticos e motivacionais. Apesar das recentes contratações, havia a constatação de que muitos servidores apresentavam excelente desempenho e elevado grau de comprometimento com a instituição. Entretanto, nos últimos anos, vinham sendo notados certa tendência de pouca participação dos funcionários nos eventos promovidos pela administração superior, a falta de interesse nos treinamentos oferecidos, o absenteísmo e o descumprimento da carga horária da jornada de trabalho. SILva (2001), em sua exposição sobre a Revisão do Modelo de Ação Fiscal, apresentou sinais de insatisfação interna, refletidos na baixa eficácia das ações fiscais, na pouca seletividade dessas ações e na insatisfação dos auditores com os resultados dos trabalhos desenvolvidos. Assim, para a implementação do programa de modernização, a Sefaz entendeu como de suma importância os componentes relativos aos recursos humanos e aos recursos tecnológicos.

Com relação ainda à capacitação dos funcionários, o Programa de Modernização contemplou diversos treinamentos, operacionais e conceituais. Dentre os últimos, pode-se destacar o Programa de Desenvolvimento de Competências, que ofereceu mais de 1.400 vagas. Os programas abordaram as disciplinas Comunicação, Motivação, Mudança Organizacional, Liderança, entre outras, reformulando muitos conceitos de trabalho na instituição. Esses treinamentos buscavam desenvolver nos funcionários novas perspectivas e visões e colaboraram para a aceitação das mudanças.

Ao longo do processo de modernização, foram utilizados mais de 15 indicadores de desempenho, incluindo previsão e realização da receita orçamentária e do gasto público, indicadores da receita tributária e indicadores internos para a instituição (Pernambuco, 2004). O Plano Estratégico de 2006 cita que as metas globais estabelecidas para 2005, de modo geral, foram superadas, reafirmando o sucesso e os benefícios do processo de modernização (Pernambuco, 2006).

\section{Teorização, diagnóstico e análise}

É preciso considerar que a caracterização diagnosticada foi baseada no passado da instituição, que se encontra atualmente em processo de mudança, decorrente do Programa de Modernização Fazendária, que ainda vigora.

\section{Caracterização organizacional}

Principais problemas organizacionais

Segundo LewIN (1951), os objetivos e as estratégias são instrumentos extremamente poderosos para organizar e coordenar os esforços de qualquer organização. Muitas pessoas não têm a percepção clara desses objetivos e dessas estratégias, tendo como agravante para o processo a dispersão e a falta de participação delas nos processos decisórios.

A estrutura voltada para decisões centralizadas da Sefaz tendia a tornar o processo de mudança mais difícil, visto que as pessoas não se sentiam parte do processo, gerando a falta de comprometimento.

Entre as causas dos problemas que vinham sendo enfrentados pela Sefaz, alguns ainda presentes, mesmo que em menor intensidade, podem-se especular os aspectos 
da cultura e estrutura organizacional, a resistência à mudança, a carência de processos de aprendizagem organizacional, as deficiências de infra-estrutura e tecnologia, a falta de capacitação e treinamentos periódicos e o pouco contato dos funcionários com a instituição, principalmente os funcionários que trabalham em regime de plantão, em postos fiscais afastados da sede, como o auditor, que trabalha 24 ou 48 horas seguidas por semana, ficando vários dias livres. Isso gera dificuldade de vínculo entre ele e a instituição. Por sua vez, a forma de trabalho por tarefas dos auditores de estabelecimento também permite a dispersão de seu horário de trabalho.

Outras causas para os problemas organizacionais da Sefaz podem estar relacionadas à falta de planejamento participativo; à falta de envolvimento dos funcionários nos processos de modernização; às dificuldades no processo de comunicação entre os níveis de decisão e a base operacional; às dificuldades resultantes de processos burocráticos internos; ao sistema de comunicação interna deficiente (somente com relação ao uso do e-mail institucional, menos da metade dos auditores utilizam-no); e à paralisação do processo de promoção e progressão para os funcionários públicos em geral. Observava-se também a presença de bloqueios à inovação na Sefaz, tais como o descrédito às novas idéias vindas da base operacional e a necessidade de assegurarse que os pedidos de informação seriam totalmente justificados, entre outros. Esses bloqueios estão relacionados à aprendizagem organizacional, detalhados adiante.

\section{Cultura organizacional}

Alves (1997) comenta que a cultura organizacional pode ser entendida, metaforicamente, como uma espécie de lente através da qual as pessoas vêem o mundo, o que as leva a considerar o seu modo de vida como o mais natural. Para o autor, a cultura traz dentro de si informações sobre o que o grupo é, pensa e faz, para que ele possa melhor lidar com o ambiente em que vive. A Sefaz, sendo uma instituição pública da administração direta, vinculada ao Poder Executivo estadual, como quase todas as instituições públicas, caracterizava-se por ser uma organização voltada para dentro,

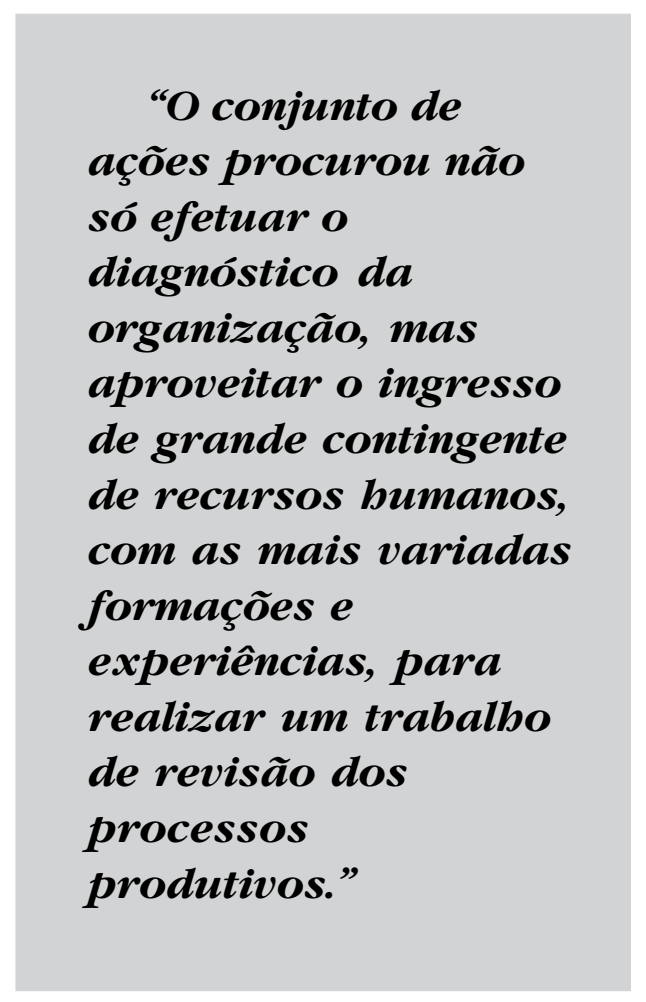

tradicional, burocrática e extremamente corporativa, portanto com suas crenças, valores, pressupostos e normas bastante consolidados pelos membros da instituição.

Os componentes burocráticos e tradicionais da Sefaz, evidenciados por sua estrutura gerencial de várias camadas e com um sistema centralizado de decisões, consubstanciavam-se como um dos pressupostos e dos valores da empresa ao 
longo das últimas décadas. Essa estrutura, além de provocar lentidão no processo de atendimento ao contribuinte e ao cidadão, causava ineficiência no processo decisório e, conseqüentemente, deficiência no desempenho da organização e no atingimento de suas metas.

Com a implantação do novo modelo de gestão, cujo foco passou a ser a gestão voltada para a obtenção de resultados, mudaram-se radicalmente algumas crenças, alguns pressupostos e alguns valores, fazendo-se necessária uma reestruturação organizacional, com diminuição dos níveis hierárquicos de sete para quatro. $\mathrm{O}$ foco de todo o gerenciamento passou a ser nos fins, isto é, na produção de resultados, para atender às necessidades da sociedade. Portanto, o sentido do gerenciamento passa a ser de fora para dentro da instituição.

Os avanços tecnológicos estiveram particularmente associados às mudanças culturais vivenciadas. Investimentos na automação da Sefaz elevaram um dos indicadores de desempenho (número de estações de trabalho por servidor) de 0,2 , em 1999, para 0,83, em 2003. Além disso, o desenvolvimento do Sistema Integrado de Informações Fazendárias (e-fisco), considerado um dos projetos mais importantes do Promofaz, com previsão de término em 2006, também trouxe fortes repercussões no processo de mudanças da instituição (Pernambuco, 2004).

\section{Estrutura organizacional}

A estrutura organizacional de uma instituição contribui para explicar e prever comportamentos, definindo como as tarefas de trabalho são formalmente divididas, agrupadas e coordenadas (RobBins, 1998). No programa de modernização, a mudança na estrutura organi zacional levou a Sefaz à redução dos níveis gerenciais. Nesse processo, foram revisadas tanto as atribuições como os processos e as atividades de cada área de negócio da Sefaz. Foram promovidos workshops para a discussão da nova estrutura e palestras de divulgação, embora na sua formulação tenha havido pouca participação do corpo funcional da Sefaz. As decisões foram centralizadas no grupo de técnicos encarregados de implementar o novo modelo da ação fiscal e na administração superior, auxiliada por uma consultoria externa.

Mesmo com a mudança na estrutura organizacional da Sefaz, ela ainda pode ser classificada como bastante verticalizada, apresentando ainda muitas divisões e subdivisões. Segundo Robbins (1998), uma organização com mais de 2.000 funcionários já é moderadamente mecanicista. Mas é inegável o melhoramento da estrutura, dentro dos elementos-chave apresentados pelo mesmo autor. Embora ele mencione a predominância de estruturas matriciais em órgãos governamentais, a Sefaz enquadra-se melhor na definição de estrutura organizacional burocrática, segundo o modelo mecanicista, que é caracterizada por tarefas operacionais altamente rotineiras, as quais são alcançadas por meio de especialização e regras muito formalizadas, tarefas agrupadas em departamentos funcionais, autoridade centralizada e tomada de decisão que segue a cadeia de comando.

\section{Aprendizagem organizacional}

A aprendizagem está diretamente relacionada aos processos de mudança organizacional. A verdadeira aprendizagem, chamada de aprendizagem organizacional de ciclo duplo por Valença (1997), caracteriza-se quando os membros da organização modificam de forma paradigmática 
os seus modelos mentais, valores, crenças e pressupostos fundamentais e, em decorrência, suas estratégias de ação. $\mathrm{O}$ autor esclarece que essa aprendizagem influencia as relações interpessoais, intergrupais e intragrupais, gerando, por conseguinte, mudanças nas teorias instrumentais da organização e no seu sistema de aprendizagem. Senge (1990) também diz que aprender em organizações significa testar continuamente nossa experiência e transformar essa experiência em conhecimento, acessível a toda a organização e pertinente ao seu propósito central.

Por outro lado, Silva e outros (1998) apresentam três estágios de ciclo de vida organizacional. A Sefaz identifica-se ainda, predominantemente, no estágio intermediário, o de formalização, principalmente no que diz respeito às políticas e regras institucionalizadas, ao poder relativamente centralizado, ao planejamento sistemático e ao conservadorismo. Outras características são: o grande porte, as rotinas defensivas, evitando-se os confrontos, e as dificuldades em "personalizar" o atendimento (que pode significar "privilegiar"), resultando em aprendizagem mais lenta. Considerando os estilos de aprendizagem organizacional mencionados por Kim (1993), na Sefaz a aprendizagem ainda está muito relacionada ao operacional, ao saberfazer, em detrimento da compreensão do por que algo tem de ser feito - a aprendizagem conceitual.

Wardman (1996) aponta alguns aspectos que podem ser impeditivos ao surgimento de comunidades que aprendem. Entre eles podemos identificar na Sefaz: a falta de planejamento colaborativo, a reflexão silenciosa, a experimentação individual, a percepção do fracasso como incapacidade e os comportamentos defensivos, ou seja, "do ataque é a melhor defesa". Essas características, entre outras aqui apontadas, são comuns à realidade de uma empresa pública como a Sefaz (cf. Quadro 1) e constituem bloqueios à aprendizagem na instituição, predominando uma estrutura mecânica e conservadora, dentro da classificação proposta por Dellagnelo (2000). Observam-se rotinas defensivas e diversos bloqueadores estruturais, que contribuem para essa situação.

Entre as rotinas defensivas, ainda persistentes, verifica-se que, constantemente, evita-se o confronto e até mesmo o simples diálogo, que é fundamental à aprendizagem. Nota-se o individualismo mencionado por Senge (1990), que gera indiferença quanto à atuação do todo institucional, sob o argumento de "estar fazendo a parte que lhe cabe" - o servidor não se interessa pelo resto e enxerga somente o imediato e nada além dos fatos. Às vezes, observa-se até mesmo forte apatia e desprezo pela "sua parte". Os contatos entre os indivíduos caracterizavam-se por ser bastante formais e praticamente não havia a participação das pessoas abaixo do topo hierárquico nos processos de decisão.

Há expectativas de que essas condições venham a se modificar com as mudanças ocorridas no processo de modernização fazendária. Iniciativas importantes surgiram nesse período, como a criação da Ouvidoria, regulamentada em 2000, e a criação do grupo de Educação Fiscal. Em 2002, a Ouvidoria registrou uma média de mais de 330 atendimentos mensais (Pernambuco, 2003). A Educação Fiscal, por sua vez, incluiu a formação de 369 novos disseminadores, envolvendo mais de 180 escolas em 67 municípios, além de sensibilizar mais de 1.800 funcionários de diversas entidades. A própria estrutura organizacional trouxe melhorias. 
Indiscutivelmente, a Sefaz encontravase com forte grau de dificuldade no aprendizado organizacional, mas, com os investimentos do Promofaz em processos de mudança, vem sendo observada a presença de pequenos grupos que podem encaixar-se no modelo cognitivo de aprendizagem, verificando-se, assim, nova forma de pensar. Esses grupos podem ser classificados no tipo de aprendizado adaptativo e individual. O Quadro 2 destaca as principais ações que visaram a melhorias ao público interno da instituição.

\section{Mudança organizacional}

Além das mudanças relacionadas à cultura, à aprendizagem e à estrutura organizacionais, para o entendimento das mudanças promovidas na Sefaz, é preciso considerar o papel do planejamento estratégico sobre elas e o modelo de gestão adotado no programa de modernização. O planejamento estratégico é uma disciplina que tomou vulto na década de 1970, ressaltando a influência do ambiente externo nos processos internos das organizações.

Quadro 1: Práticas e ações organizacionais notadas na Sefaz, que dificultam o processo de aprendizagem na instituição

- Excessos de regras e formalizações

- Dificuldades de comunicação entre os diferentes setores

- Falta de entusiasmo/motivação entre funcionários

- Inexistência de um plano contínuo de treinamento

- Falta de elementos que valorizem os funcionários

- Bloqueios à inovação

- Individualismo

- Falta de infra-estrutura organizacional e recursos para o favorecimento da aprendizagem

- Falta de integração/conhecimento do funcionamento sistêmico da instituição

- Indicadores de desempenho com ênfase em elementos quantitativos

\section{Quadro 2: Principais ações realizadas com vistas à melhoria da qualidade de} serviços prestados ao público interno da Sefaz

- Melhorias nas condições físicas de trabalho, com a aquisição de novos prédios, reformas e a aquisição de novo mobiliário

- Mudanças na sistemática de trabalho da gestão de recursos humanos

- Investimentos no Programa de Qualidade de Vida da Sefaz

- Capacitação na Escola Fazendária, que envolveu mais de 2.000 participações anuais

- Conclusão e início de capacitação pelo portal Educação a Distância

- Aquisição de novas estações de trabalho

- Diversos investimentos na área da tecnologia da informação, com destaque para a conclusão do Data Center da Sefaz

Fonte: Pernambuco (2006) - Plano Estratégico 2006. 
Ao longo da década de 1980, a incorporação dos conceitos de planejamento e de administração estratégica às teorias sobre mudança organizacional leva a que a mudança seja, ela própria, definida como estratégia de ação. A mudança não é mais encarada como algo momentâneo, tópico, mas como movimento permanente de ajuste proativo da organização às alterações dos ambientes externos e internos (FISHER, 2002).

Considerando-se todos esses conceitos e, especialmente, a definição de "mudança planejada" como "a tentativa de reformular uma organização de modo a ajudá-la a se adaptar às mudanças do ambiente externo e alcançar novos objetivos" (STONER; FREEMAN, 1992), a Sefaz tem trabalhado, nitidamente, um processo de mudança planejada, independentemente dos valores tradicionais e políticos que envolvem a instituição.

Nesse processo de mudanças, a instituição não foge à regra de ter de enfrentar as dificuldades conseqüentes dele, isto é, o processo não é simples, indolor ou de baixo custo. As três abordagens da mudança propostas por Stoner e Freeman (1992) foram realizadas na instituição: a) mudança na estrutura, com reformulação da organização e modificação no fluxo de trabalho; b) abordagem tecnoestrutural, reformulando-se a estrutura e as operações de trabalho; c) mudança nas pessoas, de atitudes, expectativas e percepções, com base em capacitação e outros eventos voltados para tal.

Também foi observada a construção de algumas interfaces estratégicas contemporâneas, como o centramento na competência básica, isto é, implementar a arrecadação, com qualidade de serviços; acompanhamento rigoroso da evolução tecnológica; e a instituição de foco acentuado no cliente e na comunidade. As duas primeiras abordagens propostas por
Stoner e Freeman (1992) receberam maiores investimentos, como se pode observar no Quadro 2 e nos demais exemplos apresentados neste trabalho. Em realidade, percebe-se que o ponto fraco do desenvolvimento do programa ainda permanece na abrangência do seu corpo funcional e na carência de política mais participativa.

Esse problema tem a ver com a análise de campo de forças impulsionadoras e restritivas (LEWIN, 1951). No processo em curso na Sefaz, observa-se grande investimento de esforços nas forças impulsionadoras, atitude que tem provocado aumento das forças restritivas, fazendo crescer as resistência às mudanças. Esse quadro precisa ser revertido, buscando-se, preferencialmente, enfraquecer as forças restritivas, para facilitar a implementação das mudanças.

As principais fontes de resistência na Sefaz estão relacionadas à cultura organizacional. Evidentemente, também estão envolvidos os interesses pessoais e as percepções dos objetivos e das estratégias da organização. Suas razões, muitas vezes disfarçadas, provavelmente envolvem as preocupações sobre competência futura, perda de controle e sensação de incerteza, principalmente entre as chefias preestabelecidas. É preciso que seja feito um trabalho de continuidade com relação ao programa de modernização, buscando maior envolvimento das pessoas.

\section{Modelo de gestão e planeja- mento estratégico}

Historicamente, segundo Chandler, em trabalho organizado por McCraw (1998), os administradores raramente alteraram sua rotina diária e suas posições de poder, exceto quando fortemente pressionados. 
Considerando a definição e a articulação entre as estratégias da organização, Porter (1980) chama a atenção para o que ele intitula de estratégia competitiva, a palavrachave do sucesso de uma organização no mundo globalizado.

As pressões internas e externas vivenciadas pelas organizações exigem mudança de postura, o que implica sair do seu mundo interior. Nesse sentido, surge a necessidade de as organizações definirem um modelo de planejamento estratégico, considerando os conceitos apresentados por Wheelen e Hunger (1992). Eles sugerem que, na formulação do Modelo de Administração Estratégica, sejam definidos a missão, os objetivos, as estratégias, as políticas, os programas, considerando as ameaças e oportunidades externas e as forças e fraquezas internas.

Wright e outros (1998) entendem que só após a organização delinear sua missão e seus objetivos gerais e específicos é que a alta administração pode formular a estratégia da empresa, em três níveis: o empresarial, o da unidade de negócio e o funcional.

Todas essas considerações são relevantes à Sefaz, mesmo sendo uma empresa pública supostamente isenta de competitividade. Ao contrário, suas responsabilidades exigem postura proativa e comprometida. Conforme já comentado, todo esse processo de mudanças decorrente do programa de modernização levou a Sefaz a estabelecer um modelo de administração estratégica que viesse a dar consistência ao sistema de gestão voltado para a obtenção de resultados.

Para atender aos novos pressupostos, a Sefaz, em parceria com uma empresa de consultoria, analisando os vários modelos esquemáticos difundidos e utilizados nas grandes organizações no mercado privado e público, adotou modelo bastante simples e de fácil implementação (Figuras 2 e 3). Como método de gestão para se atingirem as metas, foi definido o método PDCA planejar, fazer, checar, agir (CAMPOs, 2002). Sinteticamente, o novo sistema de gestão é composto de três partes: formulação da estratégia, gerenciamento pelas diretrizes e gerenciamento da rotina de trabalho, conforme esquema gráfico da Figura 2.

O gerenciamento pelas diretrizes consiste em um sistema utilizado para: a) atingir as metas para que a instituição possa cumprir a sua missão; b) resolver os problemas crônicos da organização que, apesar de muito esforço, ainda não foram solucionados; e c) atingir as metas não atingidas pelo gerenciamento da rotina do trabalho operacional.

O gerenciamento pela rotina consiste em um conjunto de ações e verificações conduzidas sobre os processos da organização. É por meio dele que as metas alcançadas são consolidadas e mantidas. $\mathrm{Na}$ formulação estratégica que tem como objetivo produzir as metas da secretaria para atender às demandas da sociedade, a metodologia utilizada no processo seguiu as etapas apresentadas na Figura 3.

Todo o processo de mudança que vem ocorrendo com a implantação desse novo modelo de gestão tem promovido grande reformulação no modo de agir e de ser das chefias. Conseqüentemente, tem-se observado a quebra de vários paradigmas, com impacto em diversos aspectos culturais bastante fortes nas organizações públicas, como, por exemplo: planejamento, flexibilização na sua estrutura burocrática, competitividade, descentralização, gestão voltada para a obtenção de resultados, integração das diretorias no estabelecimento de metas, maior colaboração entre as áreas para alcance de metas, metas institucionais e gerenciais. 


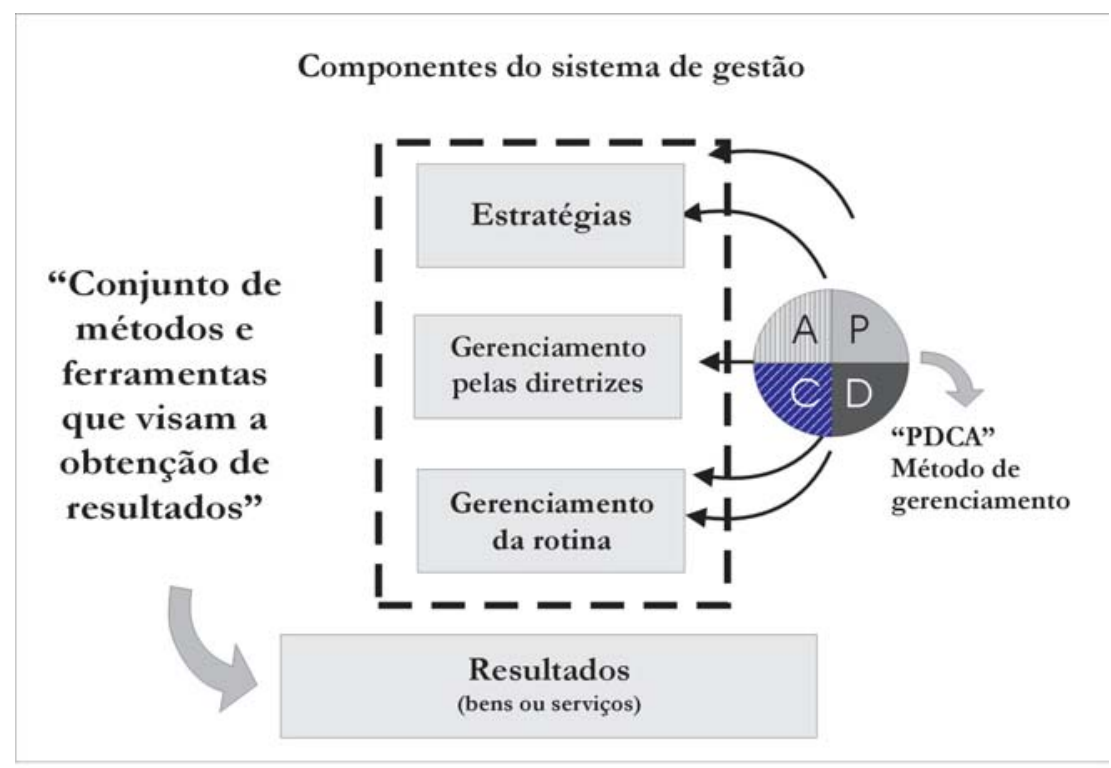

Fonte: Plano Estratégico 2002 (PERN AMBUCO, 2002)

Figura 2: Sistema de gestão adotado pela Sefaz no processo de modernização fazendária

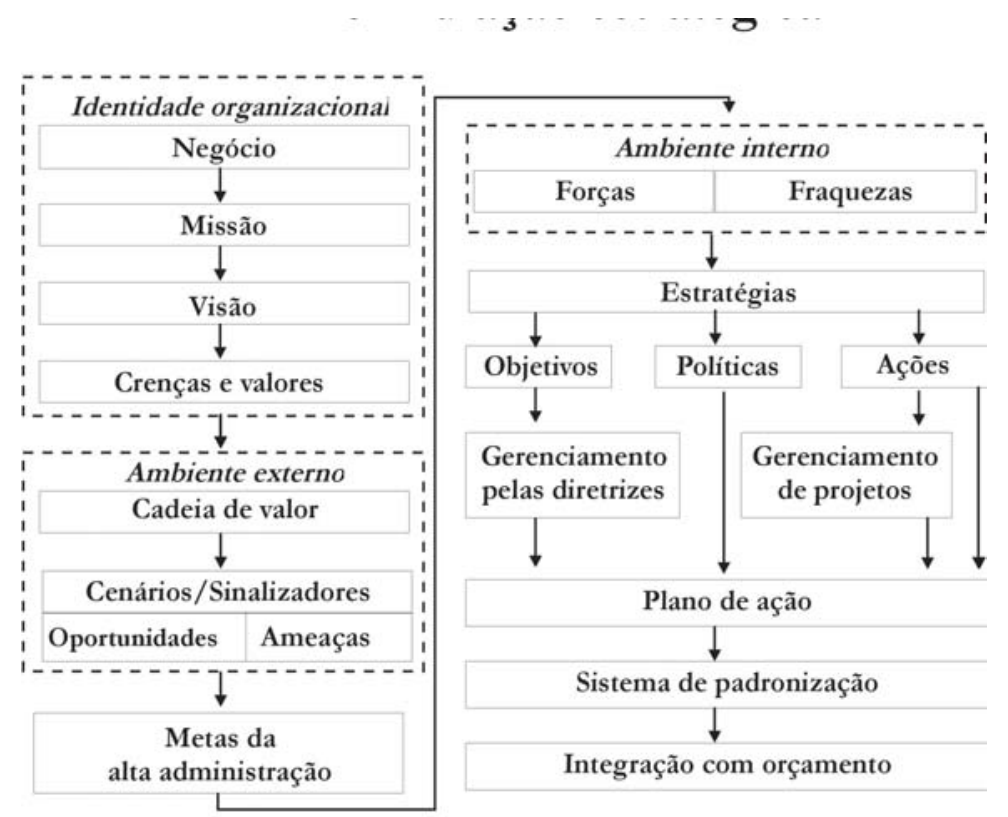

Fonte: Plano Estratégico 2002 (Pernambuco, 2002).

Figura 3: Formulação estratégica da Sefaz no processo de modernização fazendária 
Outro aspecto importante é que, além das metas tradicionais, pelas quais normalmente se avaliam apenas os aspectos quantitativos de uma tarefa, estão sendo estudados métodos de avaliação para medir o cumprimento de metas que estejam diretamente ligadas à qualidade dos serviços prestados ao cidadão, ou seja, uma avaliação sob o ponto de vista qualitativo.

O novo modelo de gestão objetivou promover mudanças nas características de a organização ser tradicional, burocrática em demasia e corporativista, tendo como incumbência desburocratizar a empresa, flexibilizar a sua estrutura e resgatar a sua competitividade. A necessidade de reduzir o custo de qualquer maneira levou a uma mudança cultural no relacionamento da organização com seus clientes (contribuintes). A organização estabeleceu o fim do trabalho empírico, passando, cada vez mais, a utilizar procedimentos científicos, apoiados em diversos instrumentos informatizados. Com relação às ações destinadas à melhoria da qualidade dos serviços prestados ao público externo, merecem destaque: a pesquisa de satisfação do contribuinte; a redução do tempo de espera para atendimento, com base em novos procedimentos; a racionalização de processos e melhorias no monitoramento dos contribuintes (Pernambuco, 2006).

\section{Impactos da tecnologia da informação}

Conforme comentado, um dos eixos do projeto da Sefaz foi a adoção de novas tecnologias de informação como instrumentos indispensáveis ao desempenho de suas atividades administrativas e ao seu processo de gestão. A incorporação desses instrumentos ao dia-a-dia da organização permitiu, entre outros benefícios, fortalecer o relacionamento com a sociedade, por meio da divulgação de informações e do atendimento via Internet, aprimorar o trabalho interno com a automação de processos produtivos, melhorar a prestação de serviços aos contribuintes, incrementar a arrecadação dos tributos estaduais e aperfeiçoar o processo de auditoria e gestão dos gastos públicos.

Nesse período de modernização, foram adquiridos mais de 1.500 novas estações de trabalho, servidores departamentais, um servidor corporativo e foi concluída a instalação da rede corporativa, interligando todos os prédios da Sefaz. Na área de sistemas de aplicação, mais de 40 novos sistemas foram desenvolvidos entre 1999 e 2005. Além disso, foi desenhada nova arquitetura de sistemas, iniciado o desenvolvimento do novo sistema integrado de informações fazendárias (e-fisco), composto de 37 subsistemas, permeando todos os processos da secretaria nas áreas tributária, administrativa, orçamentária, contábil, de auditoria e de planejamento.

Também foi criado um portal na Internet, oferecendo mais de 60 serviços e diversas informações, um portal na Intranet para uso interno e outros diversos sistemas de apoio à Ouvidoria, ao processo de arrecadação, ao controle de despesas e auditoria, como os 37 Data Mart's que compõem o Data Warehose Sefaz. Ainda foi implantado o Call Center para atendimento ao contribuinte e ao cidadão.

\section{Sistemas de informação}

Os sistemas de informação desempenham papéis importantes e vitais em qualquer tipo de organização. As razões fundamentais para o uso da tecnologia da informação nos negócios podem ser classificadas como de apoio à vantagem estratégica, à tomada de decisão gerencial e às 
operações (O’Brien, 2001). A Sefaz está migrando de ambiente de processamento centralizado, fechado e constituído de sistemas basicamente operacionais para plataforma aberta, flexível, interconectada com o ambiente interno e o externo e com sistemas desenhados para apoiar as atividades operacionais, gerenciais e estratégicas da secretaria.

Esse novo ambiente com enfoque na comunicação, além de permitir a integração de todos os sites da Secretaria da Fazenda, por meio das redes locais e de longa distância (Wan), permite maior integração com o cidadão, com os contribuintes e com o governo, por meio da Internet e Extranet. Sob o ponto de vista dos sistemas informacionais, a Sefaz, com base em moderna arquitetura de sistemas, está desenvolvendo um sistema integrado, que permitirá, além da automação de todos os processos produtivos da organização, a integração entre todas as áreas, quer seja tributária, administrativa, orçamentária, financeira ou de planejamento. Esse novo modelo permite, ainda, a prestação dos serviços via Internet, terminais de auto-atendimento, atualmente denominado de E-gov - governo eletrônico -, nas categorias G2C (governo-cidadão), G2G (governo-governo) e G2B (governoempresa). Dentre os serviços disponibilizados pela Internet, podem-se destacar os da "ARE Virtual", com mais de 60 serviços ao contribuinte, com destaque para o cadastro de contribuintes, a emissão de documentos para pagamentos e a consulta a processos e posicionamentos referentes aos contribuintes, bem como a solicitação de talonários fiscais. Também são disponibilizadas consultas para qualquer cidadão para a obtenção de informações sobre todos os contribuintes inscritos. Além disso, foi criado o Portal Fiscal, que integra as informações de todas as secretarias estaduais e a Receita Federal. Em 2002, a Sefaz foi premiada com o $3^{\circ}$ lugar na categoria "Governo para negócios" do Prêmio E-Gov 2002, com o "Portal de Serviços" da Secretaria da Fazenda de Pernambuco, concurso que se realiza desde 2002, sempre reconhecendo os melhores trabalhos desenvolvidos em TIC no Brasil (Prêmio e-Gov, 2002).

"Entre os aspectos impeditivos ao surgimento de comunidades que aprendem estão a falta de planejamento colaborativo, a reflexão silenciosa, a experimentação individual, a percepção do fracasso como incapacidade $e$ os comportamentos defensivos."

Com relação à capacidade técnica em informática dos funcionários da Sefaz, pesquisas realizadas pelo Departamento de Recursos Humanos, em 1998 (BoucinHas \& CAMPOS, 1998), registraram um potencial de apenas 4,9\% de formação suficiente para TI. Três anos mais tarde, porém, Boeckmann e outros (2001) observaram, em pesquisa baseada em questionário, que $92 \%$ dos funcionários entrevistados reconhecem que 
a TI é muito importante para o desenvolvimento de suas atividades e $91 \%$ consideram as mudanças necessárias em alguns aspectos ou extremamente necessárias, contradizendo os processos de resistência observados. Além disso, 80\% dos entrevistados consideraram suficiente a infra-estrutura de hardware e software disponível em sua unidade de trabalho. Por outro lado, os autores observaram que deficiências na comunicação interna comprometem a relação entre os usuários de TI da Sefaz e a Diretoria de TI, corroborando com a resistência à implementação de TI na secretaria.

Esses dados explicam, parcialmente, as resistências observadas na instituição ao processo de modernização tecnológica. Os autores concluíram, porém, que a Sefaz tem um corpo de funcionários medianamente capacitado em TI, o que demonstra avanços decorrentes do processo de modernização fazendária.

\section{Sistemas de suporte à decisão}

O’Brien (2001), na sua análise da expansão dos sistemas de informação no curso dos anos, destaca que, nos anos 80, desenvolveu-se o conceito de sistemas de informação executiva (EIS). Esses sistemas deviam propiciar aos altos executivos uma maneira fácil de obter informações críticas. Nos anos 90, surgem os sistemas de informação estratégica. Nesse conceito, a tecnologia da informação torna-se componente integrante dos seus processos, produtos e serviços, que ajudam a empresa a conquistar vantagem competitiva no mercado globalizado.

No que tange aos sistemas de suporte à decisão, até 1998 não existia na Sefaz sistema com tal característica. Todo o processo de decisão baseava-se apenas nas informações advindas dos sistemas operacionais ou decorrentes de anotações ou planilhas organizadas e processadas pelos gestores. A inexistência de informações sistematizadas, o isolamento e a pouca integração entre as diversas áreas da organização, aliados aos traços culturais, muito próprios das organizações públicas, quanto ao descaso com o processo de planejamento e à exagerada ênfase na autosuficiência dos seus profissionais, levaram a organização a tomar suas decisões baseadas, essencialmente, em procedimentos conservadores e empíricos, totalmente incompatíveis com a atual realidade da era da informação.

Diante desse dilema, a partir de 1999, inserido no contexto do programa de modernização da organização, iniciaramse, como projeto piloto, a modelagem e a construção do Data Warehouse (conceitualmente denominado de grande armazém). Esse Data Warehouse propiciou, além do mapeamento e da integração das diversas informações existentes nas diversas bases de dados, um modo de permitir aos funcionários, gestores ou não, apoiados em ferramentas especificas de geração e extração de informações, montarem e consolidarem todas as informações necessárias ao planejamento, à execução e ao controle das suas atividades e de seus gerenciados. Puderam, assim, extrair informações quer fossem executivas, quer fossem de apoio à decisão, com maior agilidade e rapidez na tomada de decisão, o que tem-se consubstanciado nos expressivos resultados obtidos ao longo desses anos, conforme demonstrativos do Relatório de Gestão 1999/2002 (Pernambuco, 2003). Exemplos desses trabalhos são a segmentação dos contribuintes (supermercados, farmácias, combustíveis, telecomunicações), as simulações de devolução da 
arrecadação, o controle das folhas de pagamento do estado e o controle de faixas de riscos por contribuinte, que já foram analisados por Santos e outros (2005). Os implementos na arrecadação estadual, observados na Figura 1, são resultados também desses novos modelos e sistemas.

Paralelamente a esse processo inicial de elaboração do Data Warehouse, destacase o e-fisco, conjunto de subsistemas integrados, que possibilitarão a interação entre as áreas operacionais, entre estas e as de planejamento e entre estas e as de gestão, consolidando não só as informações operacionais e internas da organização, mas aquelas advindas do ambiente externo que, de alguma forma, tenham repercussão no processo de decisão e nas atividades da Sefaz.

\section{Conclusões}

As mudanças organizacionais promovidas na Sefaz, nos últimos oito anos, foram bastante significativas. O processo de modernização fazendária pode ser percebido pelas mudanças na estrutura organizacional, na prestação dos serviços ao contribuinte e ao cidadão, e na infraestrutura física e tecnológica da instituição. A simples disponibilidade de equipamentos já promoveu diversas mudanças nos processos internos, facilitando a comunicação e agilizando as tarefas. Entretanto, diante da distribuição ampla das atividades dos funcionários pelas diversas localidades da Sefaz, característica desta instituição, permanecem as dificuldades de abrangência de todo o corpo funcional. Não há sistematização de absorção e conscientização de todo o processo de modernização tecnológica por todos os funcionários, porém os resultados alcançados não deixam dúvidas quanto aos benefícios proporcionados por essa modernização.

Além da dispersão dos funcionários, por estarem alocados em diversas e diferentes localidades, ainda há o grande problema da resistência à utilização dos novos sistemas, bem como às vantagens de comunicação que a tecnologia pode promover. A participação também na definição das atribuições e validações dos sistemas também ficou prejudicada, pela falta de comprometimento de alguns funcionários, necessário ao sucesso do processo. Ocorreu, nesse caso, o problema de esperar os "sinais fortes” para promover uma ação. É preciso que as ações sejam tomadas quando os sinais ainda são fracos.

Apesar das dificuldades, os diversos avanços tecnológicos têm provocado fortes impactos nos componentes culturais que configuram as formas vigentes de pensar e agir da organização, relativamente à sua pertinência com as demandas internas e externas. Sem a utilização dessa importante ferramenta, a informática, não se implantariam os novos modelos de gestão adotados pela Sefaz. O processo de informatização, apoiado por novo modelo de gestão da tecnologia da informação, tem propiciado não só maior integração entre as diversas áreas da secretaria, mas maior produtividade e agilidade dos funcionários na execução de suas tarefas e, principalmente, apoio aos gestores na disponibilização de ferramentas e informações necessárias ao processo de gerenciamento e tomada de decisão.

O gerenciamento está voltado à produção de resultados que atendam às necessidades da sociedade. Apoiado nessa nova visão, o processo de informatização vem oferecendo diversos serviços e informações por meio de diferentes canais de comunicação, principalmente a Internet, 
terminais de auto-atendimento e o Call Center, que atendem não só o contribuinte, mas o cidadão em geral, as instituições de classe e o governo.

Todas essas mudanças têm quebrado diversos paradigmas relacionados com a natureza das relações verticais e horizontais, com o planejamento e o alcance de metas, com a remuneração atrelada a resultados coletivos e individuais, com o atendimento e a transparência, entre outros. Contudo, verifica-se ainda a necessidade de melhoria em aspectos relacionados aos recursos humanos da instituição, envolvendo a autoestima, o comprometimento com o trabalho e a valorização do servidor.

\section{Sugestões}

Mudanças culturais estão entre as mais difíceis de serem promovidas. A aprendizagem organizacional é uma forte ferramenta para promover mudanças, colaborando no aumento do desempenho e da motivação. Garvin (1993) sugere, como passos imediatos para aprendizagem, um ambiente propício, a disponibilidade de tempo para pensar, o desenvolvimento de habilidades de análise e reflexão, a troca de idéias e o comprometimento com aprendizado.

A Sefaz precisa ainda desenvolver algumas características para estimular a criatividade organizacional, entre as quais se podem citar: desenvolver a aceitação às mudanças; encorajar novas idéias; permitir mais interação; tolerar o fracasso; estabelecer objetivos claros, dar a liberdade para alcançá-los e mostrar reconhecimento. Segundo Lewin (1951) e as teorias da aprendizagem organizacional, esses são fatores preponderantes e que devem ser considerados para que haja comprometimento do corpo funcional.
Para vencer a resistência à mudança, Robbins (1998) sugere seis táticas para serem usadas pelos agentes de mudança, das quais se pode destacar, para ser trabalhada na Sefaz, a participação. Quando se envolvem os indivíduos no processo de mudança, diminui-se a resistência e, pressupondo que eles podem contribuir de maneira significativa, pode-se obter o comprometimento e aumentar a qualidade da decisão de mudança.

Para dissipar as resistências, também se pode sugerir o envolvimento ativo dos altos gerentes nos processos de mudança, para que forneçam informações completas aos funcionários, vejam as ações passadas sob ótica positiva, promovam treinamentos e dêem continuidade àqueles já promovidos pelo programa. Motivação, recursos, planejamento e controle são fundamentais.

Sugere-se, também, uma revisão dos fatores de recursos humanos para se conceber o funcionário de qualidade como pessoa talentosa, com aumento da empregabilidade, com avaliação aberta e coletiva e o autodesenvolvimento com habilidades múltiplas. Para implementar a flexibilidade estrutural na Sefaz, é preciso considerar que a base estrutural seja voltada a processos e a equipes e as fronteiras de autoridade e responsabilidade sejam flexíveis.

Os sistemas de suporte à decisão e de informações executivas devem ser largamente utilizados, em face da grande quantidade de informações gerenciais e técnicas que circulam na Sefaz. Vale salientar que a tecnologia sozinha não faz o milagre da mudança. É preciso haver todo um conjunto de esforços, para não se correr o risco de ver bons projetos de tecnologia fracassarem por não se ter feito um trabalho paralelo com outros fatores de mudança. 
Finalmente, nesse processo, é preciso cuidado para não se formar uma "colcha de retalhos", evitando-se iniciativas não planejadas e desalinhadas, a competição negativa por recursos e a confusão nas pessoas. As áreas devem trabalhar de forma participativa e integrada no desenvolvimento de seus projetos, acompanhadas pela administração superior.

(Artigo recebido em março de 2006. Versão final em julho de 2006)

\section{Referências bibliográficas}

ALvES, S. Revigorando a cultura da empresa: uma abordagem da mudança nas organizações na era da globalização. Recife: CEPE, 1997.

Boeckmann, C. E. et al. Mudança organizacional e comunicação na melhoria da qualidade do atendimento aos usuários da tecnologia da informação na Secretaria da Fazenda de Pernambuco. 2001. (Monografia) Programa de Desenvolvimento de Habilidades Gerenciais, Escola Fazendária de Pernambuco, Consórcio FIA-USP, Esafaz, Recife..

Boucinhas \& Campos. Relatório de consultoria prestada à Secretaria da Fazenda do Estado de Pernambuco. Recife: Esafaz, 1998.

Campos, V. F. Gerenciamento pelas diretrizes. 3. ed. São Paulo: EDG, 2002.

Dellagnelo, E. H. L.; Silva, C. L. M. Novas formas organizacionais: onde se encontram as evidências empíricas de ruptura com o modelo burocrático de organizações? Ooss, v. 7, n. 19, p. 19-33, set./dez. 2000.

Fischer, R. M. Mudança e transformação organizacional. In: As PessoAs NA Organização. São Paulo: Ed. Gente, 2002. p. 147-164.

Garvin, D. Building a learning organization. Havard Busiess Review, July-Aug. 1993.

KIм, D. The link between individual and organizational learning. Sloan Management Review, 1993.

LEWIN, K. Field theory in social science: selected theoretical. New York: Harper Torchbooks. 1951.

McCraw, Thomas K. (Org.). Alfred Chandler: ensaios para uma teoria histórica da grande empresa. Rio de Janeiro: FVG, 1998.

O’Brien, J. A. Sistemas de informação e as decisões gerenciais na era da internet. São Paulo: Saraiva. 2001.

Pernambuco Estado). Secretaria da Fazenda. Plano Estratégico 2002. Recife, 2002.

Relatório de Gestão 1999-2002. Recife, [2003].

Plano Estratégico 2004-2007. Recife, 2004.

Plano estratégico 2006. Recife, [2006].

Porter, M. E. Estratégia competitiva: técnicas para análise de indústrias e da concorrência.

Rio de Janeiro: Campus, 1980. 
PRÊMIO E-Gov. Categoria "Governo para Negócios - (G2B)" 3o lugar: Portal de Serviços Secretaria da Fazenda de Pernambuco. 2002. disponível em: http://www.premio-e.gov.br/ egov-anosanteriores.asp. Acesso em: jun. 2006.

RobBins, S. P. Comportamento organizacional. São Paulo: LTC, 1998.

SAntos, A. et al. Data Warehouse: a successful case study in a Governmental State in Brazil. In: Workshop DATA GADGETs: Bringing up emerging solutions for Data Warehousing Systems. Sep. 2005. Granada, Spain.

Senge, P. A quinta disciplina. São Paulo: Best Seller, 1990.

Silva, C. L. M. da; Vieira, M. M. F; Dellagnelo, E. H. L. Ciclo de vida, controle e tecnologia: um modelo para análise das organizações. Organizações \& Sociedade, Salvador, v. 5, n. 11, p. 77-104, 1998.

Silva, A. A. Novo modelo de ação fiscal. In: SEminário Internacional de ModerniZação das Fazendas Públicas Estaduais. Set. 2001. Cabo de Santo Agostinho/ Pernambuco.

Stoner, J. A. F.; Freeman, R. E. Administração. 5a ed. Rio de Janeiro: Prentice Hall do Brasil, 1992.

Valença, Antônio C. Eficácia profissional. Rio de Janeiro: Qualitymark, 1997.

Wardman, Kellie T. Criando organizações que aprendem. São Paulo: Futura, 1996.

Wheelen, T. L.; Hunger, J. D. Strategic management and business policy. Massachussetts: Addison-Wesley Publishing Company, 1992.

Wright, P.; Kroll, M. J.; Parnell, J. Administração estratégica: conceitos. $4^{a}$ ed. São Paulo: Atlas, 1998. 


\section{Resumo - Resumen - Abstract}

\section{Mudanças organizacionais no processo de modernização da Secretaria da Fazenda do Estado de Pernambuco \\ Clara Emilie Boeckmann e Nevton Borba de Andrade}

A partir de 1998, teve início, na Secretaria da Fazenda do Estado de Pernambuco, o Programa de Modernização Fazendária (Promofaz), que promoveu diversas mudanças organizacionais, concentrando esforços em projetos estruturadores, incluindo investimentos no planejamento de tecnologia da informação (TI). Dentre os projetos de TI, destacou-se a elaboração das arquiteturas de sistemas e tecnológicas. Neste trabalho, foi realizada uma revisão dos processos organizacionais da modernização fazendária, abrangendo aspectos de cultura, mudança e aprendizagem organizacionais, confrontados com referenciais históricos e teóricos, e maior enfoque na área de tecnologia da informação. Apesar das dificuldades, o processo de informatização tem provocado fortes impactos nos componentes culturais da instituição. Sem a utilização da tecnologia da informação como ferramenta, provavelmente não se implantariam os novos modelos de gestão adotados pela Sefaz, mas se observou que a tecnologia, sozinha, não faz o milagre da mudança, sendo necessário todo um conjunto de esforços e um trabalho paralelo com outros fatores de mudança.

Palavras-chave: mudança organizacional, informação tecnológica, Secretaria da Fazenda do Estado de Pernambuco

\section{Cambios organizacionales en el proceso de modernización de la Secretaría de Hacienda del Estado de Pernambuco \\ Clara Emilie Boeckmann y Nevton Borba de Andrade}

A partir de 1998, se inició, en la Secretaría de Hacienda del Estado de Pernambuco, el Programa de Modernización Haciendaria (Promofaz), que ha promovido diversos cambios organizacionales, concentrando esfuerzos en proyectos estructuradores, incluyendo inversiones en planificación de tecnología de la información (TI). Entre los proyectos de TI, se destacó la elaboración de arquitecturas de sistemas y tecnológicas. En este artículo, se realizó una revisión de los procesos organizacionales de la modernización haciendaria, incluyéndose los aspectos de cultura, cambio y aprendizaje organizacionales, confrontados con referenciales históricos y teóricos, y mayor enfoque en la área de tecnología de la información. No obstante las dificultades, el proceso de informatización ha provocado fuertes impactos en los componentes culturales de la institución. Sin el uso de la tecnología de la información como herramienta, no se implantarían probablemente los nuevos modelos de gestión adoptados por Sefaz. Se observó, sin embargo, que la tecnología sola no hace el milagro del cambio, necesitándose un conjunto de esfuerzos y un trabajo paralelo con los otros factores de cambio.

Palavras-chave: cambio organizacional, información tecnológica, Secretaría de la Hacienda del Estado de Pernambuco. 
Organizational changes and the modernization process in the Finance Secretariat of the State of Pernambuco

Clara Emilie Boeckmann and Nevton Borba de Andrade

From 1998, the Secretariat of Finance of the State of Pernambuco (SEFAZ) initiated a process of modernization, which has promoted organizational changes, concentrating efforts in structural projects, including investments in information technology (IT) planning. Among the IT projects, it must be highlighted the implantation of systems and technologic architectures. In this paper, it is presented a review of the organizational aspects of the process of modernization, considering the organizational culture, changes and learning. Moreover, the technological modernization process has had strong impacts on the cultural components of SEFAZ. Without the use of the IT as a fundamental tool, the new model of management would probably not be adopted by SEFAZ. The paper concludes, however, that IT, alone, does not make the miracle of change: it is necessary to combine the introduction of new technologies with a set of organizational change efforts.

Key words: organizational change, information technology, Finance Secretariat of the State of Pernambuco

Clara Emilie Boeckmann

Auditora Fiscal do Tesouro Estadual de Pernambuco desde 1996. Atualmente supervisiona o setor de Desenvolvimento de Recursos Humanos. Possui MBA em Gestão de Serviços e M.Sc. em Oceanografia Biológica. Contato: $<$ clara.vieira@sefaz.pe.gov.br>

Nevton Borba de Andrade

Auditor Fiscal do Tesouro Estadual de Pernambuco desde 1994. É formado em Ciências da Computação e bacharel em Direito. Concluiu o MBA em Gestão de Serviços pela UFPE. Ocupa o cargo de Superintendente de Tecnologia da Informação da Sefaz desde 1998. Contato: <nevton.andrade@sefaz.pe.gov.br> 